\title{
GÊNEROS DE DISCURSO, ESCRITA E ENSINO
}

\author{
SPEECH GENRES, WRITING AND TEACHING
}

\author{
Jauranice Rodrigues Cavalcanti ${ }^{\star 1}$ \\ Marcela Franco Fossey ${ }^{* 2}$ \\ Marina Célia Mendonça ${ }^{* * 3}$ \\ Raquel Salek Fiad
}

Este dossiê, "Gêneros de discurso, escrita e ensino", organizado com o propósito de discutir a temática dos gêneros de discurso em sua relação com o ensino de escrita, é publicado em um momento em que a presença dos gêneros textuais e/ou discursivos, no Brasil, apresenta-se como indiscutível nas práticas de ensino tanto na escola básica quanto em contexto universitário. Esse caráter de obviedade leva, muitas vezes, a um apagamento de uma história de constituição, colocando à sombra os movimentos de sua construção social e a heterogeneidade de abordagens possíveis no trabalho didático com os gêneros.

Comecemos pelo movimento de entrada do texto em sala de aula. No final da década de 1970, no Brasil, o contexto acadêmico se organizava em torno da vontade de ver os desenvolvimentos pelos quais passavam os estudos das Ciências da Linguagem refletidos nas relações de ensino/aprendizagem de língua materna. Havia um interesse especial pelas formas como o sujeito aprende linguagem em seu trabalho com a textualidade, tanto nas atividades de escuta/leitura quanto nas de produção oral/escrita. Destaque-se, nesse contexto, a obra seminal "O texto na sala

* Universidade Federal do Triângulo Mineiro, UFTM, Uberaba, MG, Brasil. jrodriguescavalcanti@ terra.com.br

Orcid: https://orcid.org/0000-0003-3302-4001

1. Trabalho resultante de atividades desenvolvidas no Programa de Pesquisador Colaborador da Unicamp (2018-2019), sob supervisão do Prof. Dr. Sírio Possenti.

** Pós-doutoranda na Universidade Estadual de Campinas, Unicamp, Campinas, SP, Brasil. marcela.ff@ gmail.com

Orcid: https://orcid.org/0000-0002-6304-3361

2. Trabalho resultante de atividades desenvolvidas no Programa Nacional de Pós-doutorado (CAPES) (2018-2019), sob supervisão da Profa. Dra. Raquel Salek Fiad.

*** Universidade Estadual Paulista, UNESP, Araraquara, SP, Brasil. marina.mendonca@unesp.br Orcid: http://orcid.org/0000-0002-5712-2346

3. Trabalho resultante de atividades desenvolvidas no Programa de Pesquisador de Pós-Doutorado da Unicamp (2018-2019), sob supervisão do Prof. Dr. Sírio Possenti.

**** Universidade Estadual de Campinas, Unicamp, Campinas, SP, Brasil. racafiad@gmail.com Orcid: http://orcid.org/0000-0003-3077-8561 
de aula", publicada em 1984, que reúne artigos que indicavam novos caminhos para o ensino de língua materna, considerando questões relativas à variação linguística, à gramática, à leitura e à escrita. A proposta de Geraldi, presente nessa coletânea, é a de um ensino de língua portuguesa em que, a partir do texto, integram-se as práticas de leitura, produção de texto e análise linguística. O texto é, nesse movimento, centro das atividades de ensino.

A partir da década de 1990, os gêneros textuais e/ou discursivos ganham cada vez mais enfoque, ora como conteúdos de ensino, ora como instrumentos em atividades didáticas. Esse novo movimento resulta, mais uma vez, do investimento da comunidade acadêmica em pesquisas com o discurso e com a textualidade aplicados às relações de ensino/aprendizagem, em suas diversas vertentes teóricometodológicas. É, exatamente, nesse período, com a publicação dos Parâmetros Curriculares Nacionais (1997/1998), que o movimento da entrada do texto em sala de aula ganha a dimensão do espraiamento para o trabalho com os usos da linguagem, em suas diversas manifestações, e com os gêneros. Segue-se aos Parâmetros a publicação de materiais didáticos que reforçam esse movimento em direção ao trabalho com os gêneros em sala de aula.

Com base em estudos elaborados por Bunzen (2004) e Motta-Roth (2008), podemos identificar, nas pesquisas desenvolvidas no Brasil fundamentadas em diferentes perspectivas de teorias de gêneros, algumas escolas teóricas: a Escola de Sidney, baseada em postulados da Linguística Sistêmico-Funcional, a Escola de Genebra, que desenvolveu o Interacionismo sociodiscursivo, a Escola Americana ou Nova Retórica, com foco nas inter-relações entre texto e contexto e a Escola Britânica de ESP (English for Specific Purposes), com foco na organização retórica dos gêneros. Destacamos também a força que a leitura do ensaio "Os Gêneros do Discurso", de M. Bakhtin, gerou nas relações de ensino de línguas, influenciando também os Parâmetros citados.

Esses movimentos de entrada do texto e dos gêneros na sala de aula, nas últimas décadas, no Brasil, apresentam-se bastante diversificados - não somente pelas várias abordagens teórico-metodológicas (algumas representadas neste dossiê), mas também pelas consequências que a opção por uma delas pode produzir nas práticas de ensino/aprendizagem. Essas consequências estão relacionadas, por exemplo, com a forma como se dá o trabalho com e sobre a linguagem ou, ainda, com a forma como se dá a relação do sujeito-aluno com o seu texto.

O trabalho com e sobre a linguagem ganha uma nova dimensão quando é pensado a partir da textualidade e dos gêneros: interessariam às práticas escolares explorar, nas aulas de línguas, as questões relativas ao uso linguístico (variação 
linguística, questões de estilo relativo ao texto ou gênero, questões de ortografia e uso de norma linguística relativas à textualidade produzida e/ou lida). A diversidade de práticas de ensino, em nossa percepção, gira em torno da concepção de gênero ou texto, em que são colocadas (ou não) em foco as formas de constituição e funcionamento dos gêneros e dos textos, considerando (ou não) as relações históricas, sociais e intersubjetivas fundantes de sua materialidade e funcionamento, considerando (ou não) suas diversas manifestações e modalidades, isto é, sua heterogeneidade. Assim, há enfoques didático-pedagógicos dos gêneros que abrem menos ou mais espaço para um trabalho com e sobre a linguagem, no primeiro caso, os estudos de gêneros seriam adicionados ao trabalho com linguagem, como em seções separadas no bloco do conteúdo de ensino, e no segundo caso, os estudos partem dos gêneros para entender o uso que os sujeitos fazem dos textos, nas diversas esferas de atividade presentes na vida dos estudantes.

Por sua vez, as consequências de diferentes abordagens da textualidade e dos gêneros nas relações do sujeito-aluno com o seu texto, em práticas de escrita, estão diretamente relacionadas à concepção de linguagem, concretizada em atividades linguísticas/linguageiras, como espaço de constituição da subjetividade. Assim, a escrita de gêneros envolveria, se se considerar a escrita como espaço de constituição (ou de manifestação) de subjetividade e intersubjetividade, temas como identidade, autoria, atuação sobre o outro, que também são abordados diferentemente a depender das perspectivas teóricas de gêneros que se assume.

Entendemos que a temática da escrita dos gêneros atingiu, de forma irreversível, o contexto educacional brasileiro, desde o nível da escola básica até o universitário, atingindo, consequentemente, a formação de professores. Neste sentido, observamos, também, que a relação entre professor e aluno tem sido objeto de reflexão de educadores e profissionais preocupados com ensino/ aprendizagem de linguagem. A noção de linguagem e de educação que constitui o "saber" do professor é fundante de sua prática docente. Não poderia ser diferente a situação se considerássemos seu "saber" sobre os gêneros textuais ou discursivos, que têm sido tomados, nas últimas décadas, mais como conteúdos de ensino do que instrumentos para a prática didática. Assim, em cursos de formação docente, encontrase, frequentemente, a preocupação de oferecer ao professor conhecimento sobre uma ampla variedade de gêneros textuais e/ou discursivos, inclusive os relacionados ao contexto digital, de forma a capacitá-lo para o trabalho com linguagem em sala de aula. No entanto, essa atitude de empoderamento do professor, em cursos de formação (que pode acabar por apenas oferecer um catálogo de gêneros), pode deixar de enfocar aspectos que nos parecem essenciais, e que envolvem a relação 
pedagógica, na alteridade fundante do "fazer-se professor em relação ao outroaluno". Acreditamos que uma atitude que vai no contrafluxo desse movimento é o empoderamento que passa, necessariamente, por uma discussão dos gêneros textuais/discursivos a partir de uma reflexão sobre as relações de ensino/aprendizagem, relações estas que norteiam toda a abordagem do conteúdo de ensino.

Assim, o fato de a temática da escrita dos gêneros estar, em boa medida, consolidada no Brasil não significa que seja consensual e tranquila sua presença entre nós. Essa diversidade, pelos debates que pode suscitar sobre as práticas de escrita, é saudável e aponta para novas construções da realidade do trabalho com a produção de textos em sala de aula.

Este dossiê apresenta, nesse contexto de diversidade teórico-metodológica e de opções didático-pedagógicas, três eixos temáticos, que entendemos ser um bom panorama das pesquisas em andamento. Assim, organizamos os artigos considerando esses eixos: o ensino de gêneros em língua materna no ensino básico, o ensino de língua estrangeira por meio de gêneros e o ensino em contexto universitário.

O artigo de Lucas Vinicio de Carvalho Maciel, "Reflexões literárias e filosóficas na base de 'os gêneros do discurso': considerações para o ensino de escrita", volta-se para a discussão de aspectos literários e filosóficos presentes em "Os gêneros de discurso" de M. Bakhtin. Na avaliação do autor, tais aspectos não costumam ser lembrados quando da leitura do texto do pensador russo, lacuna que explicaria abordagens que tomam os gêneros por objeto de ensino, mas reduzem sua complexidade, partindo do texto para um suposto contexto e não da vida para o texto, como preconiza Bakhtin. Para ilustrar a diferença entre as duas abordagens, Maciel apresenta a análise de uma receita culinária.

Marina Célia Mendonça, no artigo "Produção de textos em material didático para o Ensino Médio: questões sobre subjetividade e gêneros", discute os modos de presença da subjetividade/intersubjetividade no discurso sobre a produção textual em Língua Portuguesa no PNLD-2018, relacionando essa posição com práticas de escrita de gêneros a partir de uma coleção didática para o Ensino Médio. Sua proposta de reflexão parte de uma vasta revisão teórica sobre o tema da subjetividade/intersubjetividade nas práticas de escrita, considerando diferentes abordagens (Psicolinguística, Linguística do texto, Nova Retórica, Análise do Discurso francesa, Estudos Bakhtinianos, Aquisição da escrita, Novos Estudos do Letramento, entre outras). Mobilizando, nas análises, as noções de autoria, indícios de autoria, protagonismo e gênero, conclui que ainda que haja ganhos evidentes na mobilização da noção de gênero para a prática de escrita em contexto escolar, especialmente no que diz respeito à consideração da "situacionalidade"/"contextua- 
lização" da proposta de escrita, ainda há o que melhorar. Mais especificamente, a autora aponta como as propostas analisadas não exploram o projeto de dizer dos alunos-autores, havendo, consequentemente, pouco espaço para a manifestação de subjetividade nas práticas escolares de escrita.

Ainda no eixo ensino de gêneros em língua materna no ensino básico, Cícero da Silva analisa, no artigo "Gênero Caderno da Realidade nas práticas educativas da Pedagogia da Alternância", o Caderno da Realidade (CR), instrumento didáticopedagógico de unidades de ensino que assumem o sistema educativo da Pedagogia da Alternância (PA). Esse sistema, nascido na França na década de 1930 e presente no Brasil desde 1969, se caracteriza pela proposta de educação de crianças e jovens camponeses articulada a temáticas e a práticas cotidianas da vida no meio rural, integrando, assim, o meio educativo (escola) e o meio socioprofissional (família/ propriedade) a seus instrumentos pedagógicos. O objetivo do autor é responder à pergunta: "como se constitui o Caderno da Realidade, enquanto gênero discursivo, nas práticas educativas dos Centros Familiares de Formação por Alternância (CEFFA)?". A partir de uma revisão bibliográfica sobre a $\mathrm{PA}$ e o $\mathrm{CR}$ e de análises de dados gerados em um curso voltado para alunos do $1^{\circ}$ ano do Ensino Médio de uma CEFFA, e considerando a perspectiva bakhtiniana de gêneros do discurso, o autor conclui que o CR rompe a tradição de inserção do gênero na sala de aula exclusivamente para fins de ensino, exatamente por se tratar de um gênero que é produzido em um contexto escolar diferenciado, cujo traço principal é integrar escola, família e comunidade.

No artigo "Mapeando a escrita de estudantes do ensino fundamental: em foco o artigo de opinião", Cleiton Reisdörfer Silva e Francieli Matzenbacher Pinton partem de três aportes teóricos - a noção de gênero da Sociorretórica, o Modelo CARS e a Gramática Sistêmico-Funcional - para analisar as características linguístico-discursivas recorrentes em 59 artigos de opinião produzidos por estudantes do $9^{\circ}$ do Ensino Fundamental em contexto de sala de aula. Essa análise tem como objetivo compreender como os estudantes escrevem em uma determinada situação comunicativa visando ao desenvolvimento de atividades didáticas que privilegiem um contexto situado de ensino de escrita e favoreçam o aprendizado dessa atividade. A análise mostra que quatro movimentos e passos da estrutura retórica do gênero artigo de opinião estão presentes nos textos dos alunos - Contextualização, Apresentação da tese, Defesa da tese e Síntese e reiteração -, sendo que os movimentos de Apresentação da tese e Defesa da tese são os mais frequentes no corpus analisado. Esses resultados podem contribuir para o ensino de gêneros já que apontam o que precisa ser ensinado aos alunos. 
$\mathrm{O}$ artigo "O (re)conhecimento da sócio-história nas capacidades de significação: conceitos necessários para operacionalização de linguagem e didatização de gêneros", de Everton Gelinski Gomes de Souza e Lidia Stutz, apresenta contribuição teórica à discussão da operação de linguagem denominada (re)conhecimento da sócio-história do gênero no quadro das capacidades de significação. Os autores adotam como fundamentação teórica pressupostos do interacionismo sociodiscursivo e, neste artigo, retomam a proposta das capacidades de significação presente em trabalhos anteriores de Lidia Stutz. Para a discussão deste artigo, enfocam duas produções do gênero borror short story, a primeira escrita por um estudante de $9^{\circ}$ ano, numa escola da cidade de Guarapuava/PR; a segunda, criada por um escritor acanônico, publicada em um sítio de horror stories. Analisam as capacidades de significação nessas produções, com o objetivo de se elucidar as operações de linguagem previstas nos trabalhos anteriores e de contribuir para o conhecimento das capacidades de significação por parte de professores de línguas e de pesquisadores.

Enfim, no último artigo desse eixo temático sobre o ensino de língua materna, "TDIC na educação básica: perspectivas e desafios para as práticas de ensino da escrita", Ana Lúcia Tinoco Cabral, Nelci Vieira de Lima e Sílvia Albert exploram temática emergente, considerando orientações recentes da Base Nacional Comum Curricular para o ensino de Língua Portuguesa, que destacam a importância do trabalho com leitura e escrita de gêneros em contexto digital. As autoras, assumindo uma perspectiva centrada nos estudos dos multiletramentos, apresentam reflexão sobre posts de fotos do Perfil Studigran, da rede social Instagran, tendo em vista a multimodalidade e formas de relação eu/outro que se manifestam nas postagens. Apresentam, então, possíveis estratégias para o trabalho com escrita na Escola Básica, considerando o contexto digital.

Outro artigo que explora a produção escrita em contexto digital é o de Adriana Fischer, Camila Grimes e Mariana Aparecida Vicentini ("A escrita gamificada de fanfictions com o apoio de tecnologias digitais em um clube de inglês"). Este texto insere-se, neste dossiê, na temática do ensino de língua estrangeira a partir de gêneros, no caso, do ensino de língua inglesa com leitura e escrita de fanfiction. As autoras, na perspectiva dos Novos Estudos dos Letramentos e adotando a concepção de linguagem dos estudos bakhtinianos, discutem resultados de pesquisa em que estudantes de um Clube de Inglês vivenciam a prática de escrita de uma fanfiction com o apoio das TD e da gamificação. Destaque-se, entre os resultados da pesquisa, a autonomia que o processo de gamificação das fanfictions permitiu desenvolver nos estudantes. 
Em "A elaboração de tarefas para o ensino de língua portuguesa a partir da teoria bakhtiniana de gêneros do discurso", Maíra da Silva Gomes e Letícia Grubert dos Santos propõem uma reflexão sobre critérios de elaboração e de avaliação de tarefas de produção escrita para o ensino de Português como Língua Adicional (PLA). O trabalho visa contribuir para a formação do professor de PLA, que, como destacam as autoras, é, ainda, uma área carente de atenção. Além disso, defendem a importância de se assumir uma perspectiva bakhtiniana de gêneros do discurso na elaboração e avaliação desse tipo de material, como forma de promover propostas de atividades que possibilitam o engajamento do aluno em situações plausíveis de interações comunicativas.

Neste eixo temático do ensino de língua estrangeira, ainda se insere o artigo "Produção escrita em livros didáticos de espanhol: uma análise de coleções aprovadas no PNLD", de Luciana Maria Almeida de Freitas e Carolina Tovar Albuquerque, que examinam atividades de produção escrita presentes em livros didáticos de espanhol, tendo por suporte teórico as contribuições do Círculo de Bakhtin acerca de gêneros de discurso e de pesquisadores que abordam o ensino da escrita. A análise das autoras mostra que as duas últimas coleções aprovadas pelo Programa Nacional do Livro Didático, ao contrário das anteriores, apresentam propostas de produção escrita que a tomam como um processo (e não um produto) que envolve diferentes saberes.

Enfim, neste dossiê, as práticas de escrita em contexto universitário estão contempladas no artigo "Universidade e produção de conhecimento na formação inicial: uma estratégia didática para o ensino da escrita acadêmica", de Janaína Zaidan Bicalho Fonseca, que apresenta resultados de pesquisa em aprendizagem de escrita em contexto acadêmico. A autora analisa resumos/abstracts redigidos por alunos de um curso de Matemática; a atividade, desenvolvida a partir de retextualização de um artigo científico, solicita do acadêmico que se coloque na posição de autor do artigo lido e considere, como contexto de recepção do resumo, leitores do portal de periódicos da Coordenação de Aperfeiçoamento de Pessoal de Nível Superior (CAPES). Uma contribuição desse artigo para o dossiê é o tratamento que a autora dá à noção bakhtiniana de gênero do discurso em sua utilização em práticas de escrita acadêmica, em que são enfocados não somente aspectos relativos ao tema, forma composicional e estilo dos resumos, mas sobretudo o projeto de dizer do acadêmico, tendo em vista sua relação com o artigo retextualizado e os interlocutores previstos.

Também no eixo temático sobre o ensino em contexto universitário, em especial aquele voltado para a formação de professores de língua materna, Sandoval Nonato, 
em "Escrita, ensino de língua portuguesa e formação do professor", discute o estatuto da escrita como componente curricular da disciplina Língua Portuguesa e apresenta um panorama mostrando os modos como a produção escrita é abordada no percurso histórico de constituição do ensino de língua portuguesa, defendendo a ideia de que a observação desse percurso possibilita tornar inteligível alguns desafios do ensino da escrita na escola pública brasileira atual, sobretudo do ponto de vista da formação docente. Para comprovar sua tese, o autor analisa o processo de implementação de um projeto de ensino, valendo-se do gênero de discurso relatório de estágio.

A diversidade na abordagem dos gêneros em práticas de escrita, que se encontra neste dossiê, nos parece indício de que os movimentos de que falamos estão consolidados, mas não estanques, na construção de propostas de ensino/ aprendizagem. Esperamos ter dado ao leitor, com a organização do dossiê, oportunidade de compartilhar dessa heterogeneidade que nem sempre se mostra para o observador desavisado.

\section{REFERÊNCIAS}

BUNZEN, C. (2004). O ensino de "gêneros" em três tradições: implicações para o ensino aprendizagem de língua materna. In: COVRE et al. (Org.). Quimera e a peculiar atividade de formalizar a mistura do nosso café com o revigorante chá de Bakbtin. São Carlos: Grupos de Estudos dos Gêneros do Discurso.

GERALDI, J. W. (org.). (1984). O texto na sala de aula. 2.ed. Cascavel: Assoeste.

MOTTA-ROTH, D. (2008). Análise crítica de gêneros: contribuições para o ensino e a pesquisa de linguagem. D.E.L.T.A., 24, p. 341-383.

Recebido: 17/10/2019

Aceito: 17/10/2019

Publicado: 18/10/2019 